\title{
KETRAMPILAN DASAR MENGAJAR
}

By. Yowenus Wenda, M.Pd

Sekolah Tinggi Teologi Gereja Injili Di Indonesia Sentani, 5 Maret 2015 
MENGELOLA

MEMBURA

MENUTUP

\section{DISKUSI}

VARIASI

BERTANYA

MENJELASKAN

MENGUATKAN 


\section{Membuka Pelajaran}

\section{Pengertian}

Membuka pelajaran adalah usaha pengajar untuk mengkondisikan mental peserta didik agar peserta didik

siap dalam menerima pelajaran 


\section{Tujuan Membuka Pelajaran}

\section{Grab \\ - Menarik perhatian peserta didik \\ - Gaya - Tayangan - Interaksi}

\section{Link}

\section{Outcome}

Structure

Stimulus
- Menghubungkan pengetahuan lama - baru

- Tujuan dan tingkat keberhasilan dengan antusias

- Pokok bahasan - cara pendekatan

- Rangsang ketertarikan

- Motivasi-minat-rasa ingin tahu 


\section{Membuka Pelajaran}

\section{Perkenalan}

- Nama-Panggilan-KompetensiRamah-jangan basa basi

\section{Apersepsi}

- Link Pengetahuan lama pengetahuan baru

Tujuan

\section{Motivasi}

Deskripsi Pokok Bahasan
- Ruang lingkup materi- pokok bahasan dan metode 


\section{MENUTUP PELAJARAN}

\section{Pengertian}

keterampilan

\section{pengajar \\ dalam}

mengakhiri

kegitan inti

pelajaran

\section{Tujuan}

Merangkum materi

yang telah dibahas.

Mengetahui tingkat pencapaian peserta.

Tingkat keberhasilan pengajar dalam proses belajar pengajar. 


\section{Menutup Pelajaran}

\section{Review}

- Merangkum materi yang telah dibahas

- Mengetahui tingkat pencapaian peserta didik

- Tingkat keberhasilan pengajar eedback dalam proses belajar mengajar

- Mengaitkan dengan materi berikutnya 


\section{Menjelaskan Materi}

\section{Pengertian}

Menyajikan materi secara sistematis, sehingga mudah dipahami.

Menyampaikan informasi dan fakta.

Menjelaskan:

Apa, Bagaimana, Mengapa.

\section{Tujuan}

Membimbing memahami konsep, prinsip.

Membantu memecahkan Masalah.

Melatih mandiri dalam mengambil Keputusan. 


\section{Prinsip Menjelaskan}

disesuaikan kemampuan dan karakteristik peserta

\section{diselingi tanya jawab}

Materi dikuasai secara baik oleh pengajar

\section{sesuai dengan tujuan pembelajaran}

bermanfaat dan bermakna bagi peserta didik

disertai dengan contoh yang kongkrit 


\section{Ketrampilan Bertanya}

\section{Pengertian}

Ucapan atau

pertanyaan yang

dilontarkan

pengajar yang

menuntun respon

atau jawaban

dari peserta didik.

\section{Tujuan}

Memotivasi: terlibat dalam interaksi

Melatih mengemukakan pendapat

Meningkatkan kemampuan berfikir

Mencapai tujuan belajar 


\section{Prinsip Ketrampilan Bertanya}

\section{Satu masalah}

\section{Berikan waktu berfikir}

\section{Pertanyaan singkat dan jelas}

\section{Bahasa sederhana}

\section{Pertanyaan langsung secara random}

Sesuaikan kemampuan-kesiapan peserta 


\section{Memberikan Penguatan}

\section{Pengertian}

Tindakan atau respon terhadap suatu bentuk perilaku yang dapat mendorong munculnya peningkatan kualitas tingkah laku tersebut di saat yang lain

\section{Tujuan}

Membangkitkanl

memelihara motivasi

Mengontrol dan memodifikasi tingkah laku kurang positif,

Menumbuhkan

kemampuan berinisiatif

Mendorong munculkan tingkah laku produktif 


\section{Prinsip Memberikan Penguatan}

\section{Kehangatan dan keantusiasan}

\section{Kesan positif kepada peserta}

\section{Berdampak terhadap perilaku}

positif

Dapat bersifat pribadi atau kelompok 


\section{Memberikan Penguatan}

\section{Komponen}

Penguatan verbal: bagus, tepat, benar, hebat, jawabanmu sangat tepat, dII

Penguatan non verbal:

Tepuk tangan, senyuman, hadiah , dll 


\section{Membuat Variasi}

\section{pengertian}

Kemampuan menggunakan

berbagai macam

variasi dalam

proses

pembelajaran

\section{Tujuan}

Menghilangkan kejemuan

\section{Mempertahankan} kondisi optimal belajar

Meningkatkan perhatian dan motivasi peserta

Memudahkan pencapaian tujuan pengajaran 


\section{Membuat Variasi}

\section{Bentuk}

\section{Gaya mengajar}

\section{Penggunaan media}

Pola interaksi

\section{Metode Pembelajaran}

Memberikan penguatan 


\section{Membimbing Diskusi}

Pengertian
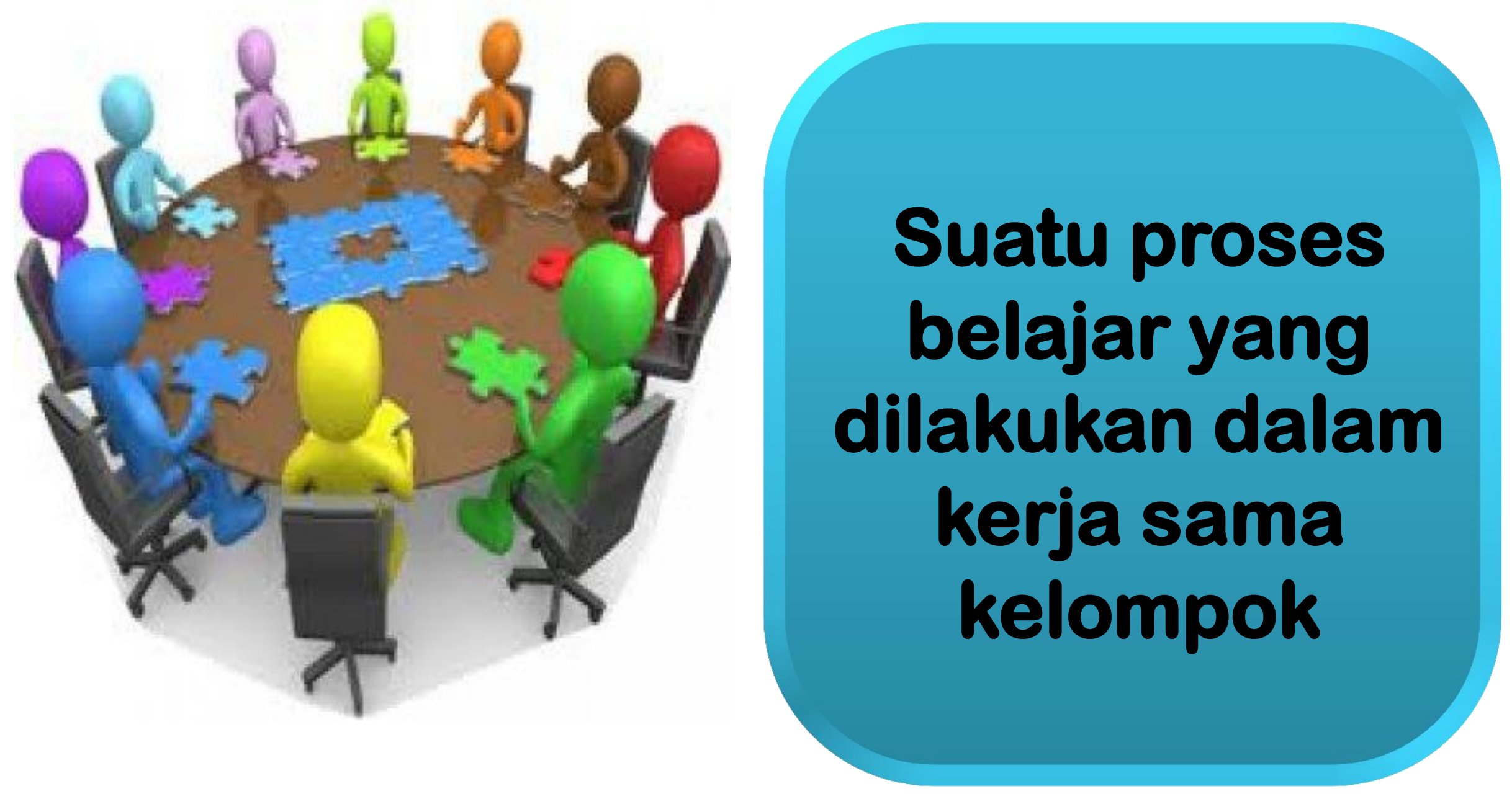


\section{Tujuan Membimbing Diskusi}

\section{Memecahkan suatu} permasalahan

Mengkaji konsep atau prinsip

Melatih kerjasama 


\section{Prinsip Membimbing Diskusi}

\section{Suasana menyenangkan}

\section{Berikan waktu yang cukup}

\section{Perencanaan dan persiapan matang}

\section{Pemilihan topik}

Penetapan besarnya kelompok

\section{Pengaturan tempat duduk}

Rencanakan diskusi secara sistematis 


\section{Hindari}

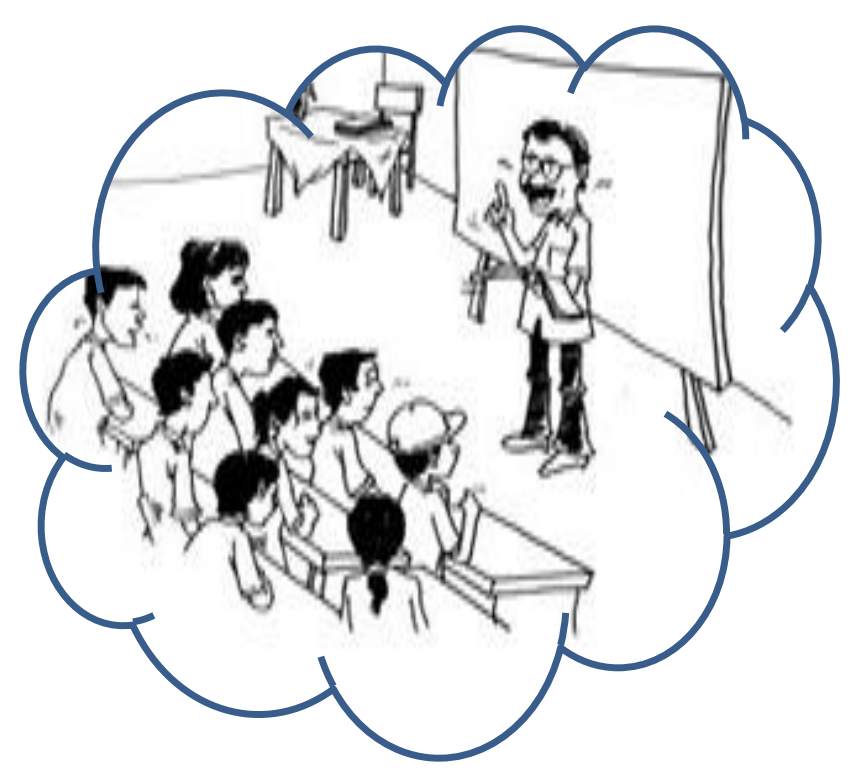

Tidak memberikan kesempatan yang cukup kepada peserta

Membiarkan diskusi dikuasai oleh peserta didik tertentu

Membiarkan peserta didik tidak aktif

Tidak merumuskan hasil diskusi dan tidak membentuk tindak lanjut 


\section{Mengelola Kelas}

\section{Pengertian}

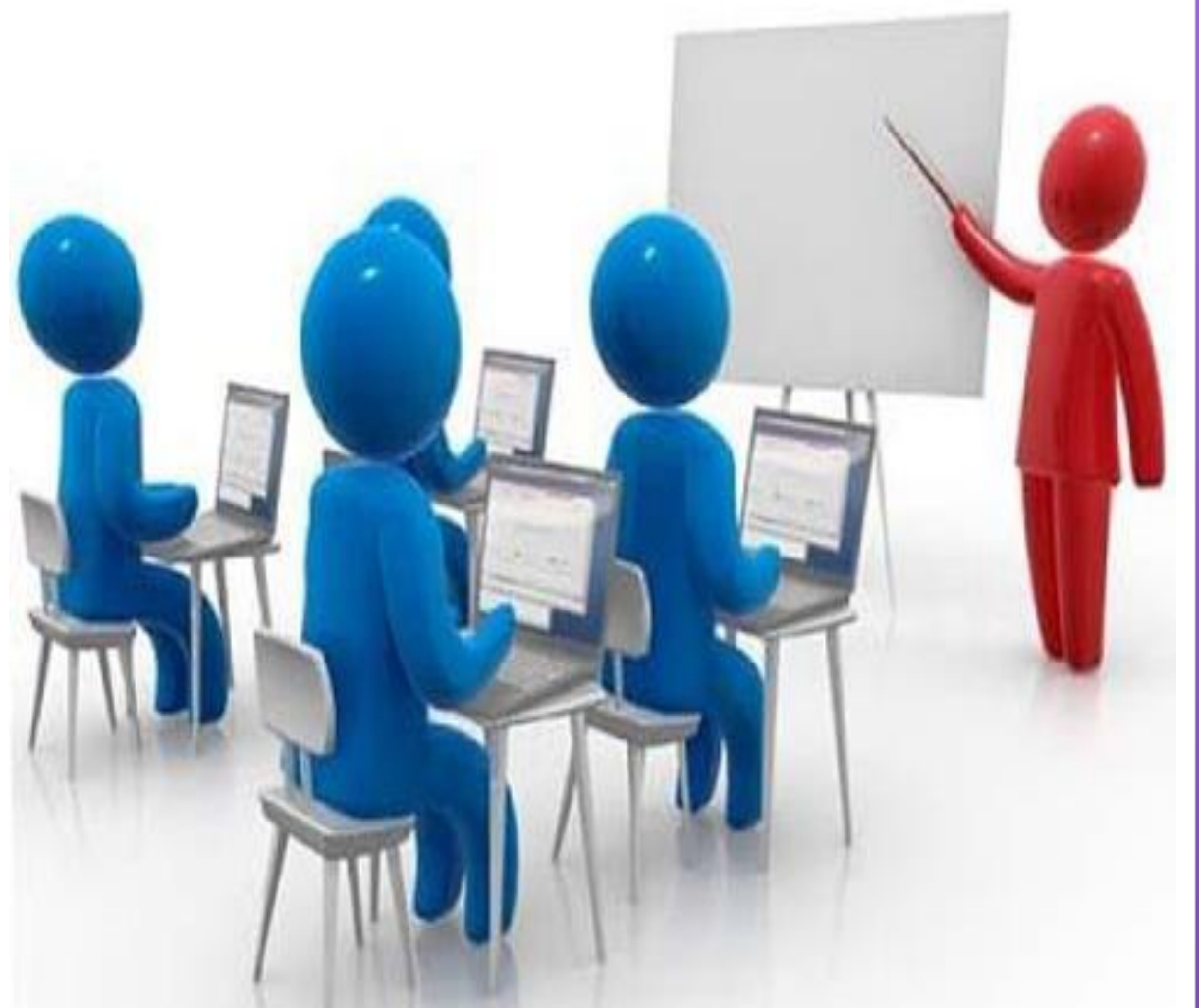

Kemampuan pengajar dalam mewujudkan dan mempertahankan suasana belajar mengajar yang optimal 


\section{Mengelola Kelas}

\section{Tujuan}

Membuat kondisi belajar yang kondusif

Menghilangkan hambatan Proses

pembelajaran

Melayani dan membimbing perbedaan individual 


\section{Bentuk Mengelola Kelas}

\section{Memusatkan perhatian,}

\section{Menunjukkan sikap tanggap,}

\section{Menegur,}

\section{Membagi perhatian,}

\section{Memberi petunjuk yg jelas,}

Memberi penguatan. 


\section{Prinsip Mengelola Kelas}

\section{Luwes (mudah disesuaikan)}

Hangat dan Antusias (bersemangat)

\section{Menggunakan Variasi}

\section{Memberikan Tantangan}

\section{Menanamkan Disiplin}

\section{Menekankan hal positif}


- memBuka

- MenuTup

- MenJelaskan

- Penguatan

- BerTanya

- Variasi

- Diskusi

- Mengelola 


\section{IMPLIKASI}

\section{Keberanian dan percaya diri dalam mengajar}

Mengajar lebih sistimatis dengan mengikuti prosedur yang benar

\section{Selalu dengan persiapan yang matang}

Mengadakan variasi dalam penggunaan media, metode, dan interaksi dalam mengajar 